\title{
To Homestay or to Stay Home: The Canadian-Japanese Experience
}

\section{Erin Crealock, Tracey M. Derwing, and Martha Gibson}

The experiences of 19 Japanese high school students in a homestay program are described. They were interviewed three times during their academic year in Canada; 13 of the students were interviewed again in Japan four months later. Although students made gains in English proficiency, several expressed dissatisfaction with the organization of the homestays. They were distressed by the lack of information provided prior to departure and the inaccurate representation of their homestay environments. Students complained about lack of access to counselling promised. Despite significant agency fees, no tuition was paid to schools, no stipend was paid to homestay families, and the students felt that little program money was spent monitoring their progress. Although the problems associated with this particular program may be isolated, there should be no tolerance for homestays that do not safeguard the students' interests. The authors make suggestions for stricter regulations regarding agencies offering homestay experiences.

In a recent review of language study abroad, the Higher Education Funding Councils for England (HEFCE) stated that programs established for university students generally had insufficient orientation, that students were not monitored carefully, and that evaluation of the programs was inadequate (Coleman, 1997). This account echoes the problems outlined in Kinnell (1990) in a study of international university students studying in England. It appears that the problems previously identified for university students in other settings can be found in high school environments as well. The study reported here describes the Canadian homestay experiences of 19 Japanese high school students who spent the 1991-1992 school year living with host families in small towns and rural settings. The findings are taken from a larger study (Crealock, 1993) that investigated the advances made by the students in their acquisition of English and documented their social and cultural experiences. For more information on the students' language proficiency gains, see Derwing (1996).

\section{Description of the Program}

The homestay experience was offered by a nonprofit, educational exchange program, designated a charitable agency in Canada, acting under contract for a larger for-profit youth agency based in Japan. The Canadian agency made arrangements for schools, host families, and orientation programs in 
Canada. The experience was financed entirely by the students' families at a cost of approximately $\$ 10,000 \mathrm{Cdn}$. each; however, neither the school boards nor the host families were paid for their participation. In fact the main reason the organizers chose placements in rural schools was the willingness on the part of the school administrators to allow the Japanese students to attend without paying any tuition fees (personal communication to first author from the area administrator, April 1992). The policy of school boards in urban areas, on the other hand, was to charge visa students for the actual cost of their instruction.

From late July to late August the students lived with urban families and attended a four-week program of English study and orientation to Canada. At the end of August they moved to eight different schools located in seven small towns. Their long-term host families lived in these towns or in surrounding rural areas. The homestay area administrator located in the urban center was responsible for the welfare of all the students while they were in Canada. The Canadian-based homestay agency also paid a small honorarium to six local contact people across the homestay area to act as counsellors under the supervision of the area administrator. Their role was to contact students periodically regarding their progress in school and potential problems concerning host families and their adjustment to life in Canada.

The host high schools ranged in size from approximately 200 to 500 students, which is considerably smaller than the average size of an urban high school. These schools generally had few or no ESL students, as immigrants tend to settle in urban centers in the province. The Japanese students were placed in various courses in grades 10,11 , and 12 . The students chose subject areas themselves and were then placed in a grade level according to availability of space and the students' ability to handle the language requirements of the course as perceived by the school. Most schools did not provide formal ESL training to the Japanese students, although by the end of the year 10 students had been given some limited ESL instruction on a one-to-one basis.

\section{Method}

\section{Participants}

Sixteen girls and three boys, ranging in age from 15 to 18, participated in the program. They came from different locations in Japan and did not know each other until they met in Canada. They had all studied English from 3-7 years in school for an average of 4.8 years. Seven of the 19 had also studied English at a cram school or $j u k u$ from 2-7 years.

\section{Data Collection}

The first author collected linguistic, personal, cultural, and social information in a series of semistructured individual interviews of approximately an 
hour in length. The interviews were conducted when the students first arrived in late July, a second time in December, and then again in June of the following year. During the first interview, which was conducted with the aid of a Japanese interpreter where necessary, students were asked questions about their attitudes toward English and English-language learning, Englishspeaking people, and Canadian culture or lifestyles. Later interviews conducted in English only asked additional questions about issues that were salient in the first interview. The students were also asked to reflect on their homestay, cultural, and language-learning experiences, as well as any personal changes that had occurred between interviews. In the third interview they were asked if, in light of their experiences, they would choose a homestay program again. Students' views were also sought on the management of the homestay program. The first author corresponded by mail with several of the students throughout the year and conducted a final oral interview with 13 of the students four months after their return to Japan.

\section{Data Analysis}

All interviews with participants were audiotaped, and their responses were transcribed after each round. The transcripts were analyzed qualitatively for recurring themes following guidelines suggested by Miles and Huberman (1984). Finally, as patterns for the group emerged, conclusions were formulated and verified in consultation with the students themselves.

\section{Results}

\section{Students' Perceptions of School}

The students noticed several differences between the Japanese and Canadian school systems, some of which they enjoyed. They commented positively on having longer classes and shorter breaks between classes. They also liked the fact that students rather than teachers moved from class to class at breaks. Some had never experienced having spare periods, personal lockers, different students in each class, small student populations, and small class sizes. Most used the word freedom when describing Canadian schools. As Student \#6 put it, "In Canada it's good. I don't have to stay in the desk." Another difference that made a strong impression on the students was the high degree of teacher-student interaction and student participation, which was perceived to be greater than in Japan. The students reported that the teachers were helpful and caring about students' problems. School was considered to be the site of an active social scene with many student "couples." The Japanese students found this aspect, and school social life in general, intimidating at first, but much easier to adjust to once they had made friends.

On the negative side, almost half of the students felt their English language development was compromised when there was more than one Japanese student in the school. By the end of the school year, only two of the 19 
students were the lone Japanese student at their schools. Student \#10 said: "It's ... I think it's too much for one high school. We are not brave enough at first so we stick together, so it wasn't so good." Student \#12 said: "I thought I was here only. Company said it's only you." This was a serious complaint, as the students stated that language learning was the aspect of their school experience and the homestay program in general that they valued most.

\section{Students' Perceptions of Canadians and Host Families}

The students' perceptions about Canadians were initially optimistic, but as the year progressed a more balanced picture emerged. On the positive side Canadians were seen as helpful, sociable, cheerful, and open-minded. Overall the advantages of living in Canada included more time spent together as a family, more freedom at school, recreational and cultural opportunities such as camping, watching TV, reading, eating North American food, and easy access to nature. The students were impressed by Canadian family dynamics. Family members were seen to engage in a large amount of discussion and communication with each other. There were strong family bonds, despite the individuality of each family member.

On the negative side Canadians were perceived to break promises easily, and students felt that it was difficult to develop close relationships. Problems in making and keeping friends was cited as one of the most difficult aspects of the homestay experience despite the perceived advantage of being placed in a small community. As student \#4 said:

First I thought I was lucky 'cause I thought my host parents were really nice and because of that small community, so, everybody's really friendly. But I was wrong - not always-but because of such a really small community, they have their own rules. They have their own way to live so I just couldn't get used to it, because I'm from such a big city in Japan and then going to the country in Canada, so, I was just lonely.

Successful immersion in Canadian culture was further delayed for some of the students because of problems with their host family placements. In fact six of the students, or nearly a third, changed host families during the program. One student missed three months of school waiting for a last-minute, hard-to-find, host family replacement. Two students even ran away from their first host family placements. In a letter from the area administrator of the Canadian agency to the first author (personal communication, April 1992), the following explanations were documented. One student was moved as a result of a long-term illness in the first host family. Two students were relocated because of behavior problems, and one student was transferred "because the host family did not realize the extent of commitment of hosting and because they seemed to be jealous of money in the student's family." Part of the problem stemmed from the dearth of information about 
the host families and about rural life in Canada. Most of the students left Japan not knowing where or with whom they would be living, and many were left in ignorance during the orientation period in Canada. Some of the previously arranged host families changed after the students left Japan, and one student (Student \#17) believed she had been given the name of a nonexistent family to cover for the fact that no family had yet been found for her.

\section{Students' Perceptions of Rural Life}

The shock of the contrast between rural and urban lifestyles was a major issue for most of the students. As student \#2 so aptly put it, "Big. Everything big." Over half of them were from cities such as Tokyo and were not forewarned of, or prepared for, the lack of conveniences such as shopping, entertainment, and transportation in the rural areas. Because in Japanese culture it is uncommon to have to rely on others for transportation, this was a source of anxiety as well. Student \#1 said:

I don't like living in Canada, but if I lived in the city I would like that. But it's too farm country, so I can't go anywhere without car. I have to ask my host mom or dad to take me anywhere. I can't find nice clothes here, but if I live in the city I want to go shopping lots of times.

Some students had received a false impression about the lifestyle they would be leading in Canada. Student \#4 said it best: "Company's person said that we are going to go to such a big city. Like there's downtown or you can buy anything or like that. They talked like that. Then I went there. Nothing!" This perception of size and nothingness contributed to difficulties in meeting new people and visiting friends, which in turn led to feelings of loneliness and isolation for the teenagers.

\section{Students' Perception of Pre-Departure Information}

There was a resounding "No" when students were asked if they had enough information about the homestay program before they came. Most felt completely ill-prepared for their homestays, even after the orientation in Canada. Student \#3 couldn't understand why this should have been so:
Like we had lots of trouble in Canada because some students couldn't get information at all about families, about schools. But I don't know why, but family in Japan [parents], they get all information, but stu- dents they don't have anything at all, so it was not so good. We were very worried about our life in Canada. We have to go to the next city or next town but we didn't know about it at all.

There was simply not enough information available for the students to form realistic expectations about rural life. Crucial, basic information about their host families, the Canadian climate, and the type of clothing required was sorely lacking. Again, unnecessary anxiety was the result. 
One would expect any good orientation program to provide this basic information. Johnston (1993) offers some reasonable guidelines in her article on conducting effective pre-departure orientation for Japanese students going to study abroad:

The aim of an orientation is to alleviate any stress and anxiety that may be experienced by Japanese students visiting a foreign country for the first time. Culture shock and unrealistic expectations can lead to frustration and disappointment and these factors can be addressed and discussed prior to departure. (p. 7)

Judging by Student \#14's comments, this frustration was certainly not alleviated: "The company must make sure the host family is good or not. It is make me so worried, so scared." There was often no time to write the host family a letter, much less receive one back, because arrangements for most host families were not finalized before the students' departure for Canada.

All the students felt that there was a need for more information about the type and size of school they would be attending and the town where they would be living. Student \#6 said, "I just knew the address and name of school before I went to Canada. So like how many students is there and what kind of activities is there? They should tell us."

Another problem created by the lack of information about rural lifestyles was that students did not come prepared for their Canadian host families' expectations of them. Despite the fact that students arrived with the impression that they would have their own rooms, sometimes they had to share bedrooms with younger children or babies. Homestay rules also required students to "voluntarily help with household chores." Typical responsibilities usually included some housework and babysitting, expectations not nearly so common in Japanese families. This cultural difference may have contributed to the concern expressed by student \#16 on the use of the Japanese students as babysitters. "You [the company] should check the family not to use the exchange student for housework or babysitter. That's terrible."

\section{Students' Perceptions of Counsellors}

Although having one area administrator and six local counsellors for 19 students may have seemed adequate, insufficient preparation and communication on the part of the contact people upset many students. A major complaint concerned the lack of support from, and basic communication with, both the area administrator and the local counsellors. In the post-homestay interviews conducted in November, Student \#5 commented: "There were about 19 students so I think it was quite impossible for just one person [the area administrator] to take care of them." Relationships with the local counsellors were essentially nonexistent. As Student \#12 relates: 
My counsellor, she didn't do anything, but she gets money from the company. Like she had to interview once a month, but she didn't. She just did once. But all the time my parents get that interview report, but I didn't. She had to ask me and then she had to put in five level circle, but she didn't do anything; she did it by herself.

The counsellor apparently had little direct contact with the student, deciding to monitor the homestay situation through casual contact with the host parents. Student \#12 continued:

But she doesn't know about me. How does she know about my school life? She says, "I sometimes see your [host] mom or dad, so I know [about] you and I talk with [school] counsellor," but I didn't talk to [school] counsellor much. So he doesn't know about my school life or friends or anything, so like I get really mad. And then she didn't come to see me and say goodbye or anything. Sometimes I wanted help.

Sometimes I get trouble. A problem or anything, so they should help us more.

Student \#15, who had to change host families in the middle of the program, agrees that the counsellor was of no help. She says, "I didn't tell my problem with my counsellor since counsellor wasn't there for us to talk to then."

\section{Discussion and Recommendations}

Although a year's immersion in Canada and Canadian high schools resulted in significant improvement for most of the teenagers' English, the lack of basic pre-departure information for participants and participants' parents, in addition to an inadequate emotional and adjustment support system, had negative effects on what should have been a rewarding experience.

The major problem was the breakdown of communication between the larger umbrella agency in Japan and the contracted agency in Canada, precipitating communication breakdowns between agency and parents, agency and students, and parents and children. Given the sacrifice that students made in time taken from their own high school career, as well as their parents' financial investment, the homestay program coordinators should have provided adequate support and information to those who needed it. The application form for this program began with the following statement:

You will find that during the time you are in Canada you will receive constant support from your family, teachers and counselor and have the opportunity to share your culture with the many friends you will make here in Canada.

This was a promise that was not kept. Student \#19 summarized the major cause of the problems as one of lack of communication between the two 
agencies involved. "I think they didn't handle us so well because they were two companies. They were Japanese company and Canadian company that didn't communicate with each other so what Canadian company said is different from the Japanese company said."

Many problems could have been alleviated with tighter government input and supervision by the Ministry of Education (Culture and Science) in Japan, the Mombusho. Both schools and homestay families should have been closely monitored; each stakeholder's needs and expectations should have been clearly communicated in order to prevent problems before they arose. Host schools in Canada should have been provided with more information about their Japanese visitors sooner, in order to accommodate their higher expertise in some subject areas, such as math, with their level of English. Staff and students should also have been given advice and information to promote the acceptance and understanding of students of Japanese background. Host families needed more written information on differences between Japanese and Canadian culture, food, home life, and schooling to deal adequately with difficulties encountered by their charges.

Most importantly, the homestay students required more information and support, both in Japan and in Canada. It would have helped if the prospective students could have heard the experiences of past homestay students and the strategies that they used to achieve academic and social success. This information could have been offered by previous participants before students left Japan or included in the orientation in Canada. During the homestay program, students would have benefited from ongoing access to a contact person with cross-cultural experience and knowledge of Japanese in order to discuss issues such as prejudice, cultural misunderstandings, personal change, feelings of anxiety, and anticipation of reentry adjustments when returning to Japan. The contact system in place in the homestay situation reported here was not performing this function adequately.

The onus is on the administering agency or agencies to accept responsibility for the smooth operation of the homestay program for all students. Individual students cannot control all aspects of their experience, especially in an administratively disorganized atmosphere. As Morgan (1975) states:

The overall success or failure of study abroad programs does not rest with the students. In fact, probably little of it rests with them since they are often not able to understand the implications of the cultural encounter and their own adaptation to this encounter. Administrators of these programs must possess, or at least endeavor to acquire this expertise in understanding the process. (pp. 214-215)

Both parents and the governments involved (Canadian and Japanese) must increase their awareness of the guidelines and operating practices of home- 
stay programs such as this one to ensure that their money is being wisely spent.

Another practical and ethical means of alleviating some of the problems we discuss would be to reimburse both the schools and host families for costs incurred during the year, as indeed happens in many homestay programs. Taking these steps would increase the likelihood of a successful homestay experience, enhanced by both a productive learning milieu and a safe, enjoyable family environment.

The homestay institute discussed in this article is only one of many. There are several programs that work hard to ensure a harmonious experience for all parties involved: students, parents, school boards, schools, and host families. We do not intend to suggest that this particular program is representative of homestay programs in Canada. On the other hand, the problems associated with this agency were serious and should be viewed as such, even if only a small minority of programs share similar characteristics. It should not be the case that homestay teenagers wish they had stayed home.

\section{Acknowledgments}

The authors would like to thank the homestay students who responded so openly to our questions. We also thank Marian Rossiter for her assistance. For further information, contact Tracey Derwing at the Department of Educational Psychology, 6-102 Education North, University of Alberta, Edmonton, AB, T6G 2G5, Canada. E-mail: tracey.derwing@ualberta.ca.

\section{The Authors}

Erin Crealock completed her Master's degree at the University of Alberta and is now an ESL teacher in Calgary, Alberta. Tracey Derwing is the coordinator of the TESL program at the University of Alberta. Martha Gibson is a linguist who is currently teaching ESL in Edmonton.

\section{References}

Coleman, J. (1997). Residence abroad within language study. Language Teaching, 30, 1-20.

Crealock, E. (1993). The homestay experience: Its linguistic and cultural effects. Unpublished master's thesis, University of Alberta.

Derwing, T. (1996). Elaborative detail: Help or hindrance to the NNS listener? Studies in Second Language Acquisition 18, 283-297.

Johnston, B. (1993). Conducting effective pre-departure orientation for Japanese students going to study abroad. Language Teacher, 17, 7-11.

Kinnell, M. (Ed.). (1990). The learning experience of overseas students. Milton Keynes, UK/Bristol, PA: Society for Research into Higher Education and Open University Press.

Miles, M.B., \& Huberman, A.M. (1984). Drawing valid meaning from qualitative data: Toward a shared craft. Educational Researcher, 13, 20-30.

Morgan, E. Jr. (1975). Study abroad: A process of adaptation and change. International Review of Education, 21, 207-215. 